\title{
Leopoldo Zea y el existencialismo mexicano
}

\section{Leopoldo Zea and Mexican Existentialism}

\author{
José Manuel Cuéllar Moreno \\ Universidad Nacional Autónoma de México \\ jmcuellarm@hotmail.com
}

\begin{abstract}
Resumen
El artículo de 1940 de Leopoldo Zea, «El sentido de responsabilidad en la filosofía actual», es un punto de arranque para el «existencialismo mexicano». Zea acunó su idea de una «nueva filosofía» y de un «nuevo filósofo» en éste y otros artículos de juventud. La «nueva filosofía» debía ser auténtica, circunstancial, histórica, pragmática, salvífica, y debía tener como datos principales la libertad individual del ser humano y la inseguridad radical que conlleva esta libertad. Esta concepción de la filosofía fue posteriormente adoptada por el Grupo Hiperión y enriquecida con sus lecturas del existencialismo francés. El principal objetivo de este trabajo es analizar la concepción de Zea de una «nueva filosofía».

Palabras clave: Leopoldo Zea; filosofía mexicana; existencialismo mexicano; libertad; Grupo Hiperión.
\end{abstract}




\begin{abstract}
Leopoldo Zea's 1940 article, «El sentido de responsabilidad en la filosofía actual», may well be considered a milestone in Mexican existentialism. Zea developed his idea of a «new philosophy» and a «new philosopher» in this and other early writings. The «new philosophy» ought to be authentic, circumstantial, historical, pragmatic, salvific, and had to deal with individual freedom and uncertainty. This conception of philosophy was later adopted by Grupo Hiperion and enriched by his readings of French existentialism. The main purpose of this paper is to analyse Zea's characterization of the so called «new philosophy».

Key words: Leopoldo Zea; Mexican philosophy; Mexican existentialism; freedom; Grupo Hiperion.
\end{abstract}

\title{
Introducción
}

El existencialismo mexicano (1947-1952) tuvo como protagonistas a los miembros del Grupo Hiperión y como principal promotor y padrino a Leopoldo Zea (1912-2004). Este movimiento filosófico bien puede ser entendido como una rebelión en contra de la ortodoxia heideggeriana propugnada por José Gaos (1900-1969); como una recepción original del existencialismo francés (Gabriel Marcel, Jean-Paul Sartre, Maurice Merlau-Ponty); como la búsqueda de una filosofía nacional (que movilizara categorías autóctonas y que prescindiese, por fin, del «utensilio europeo»); y como una última batalla por la independencia cultural. «México será culturalmente independiente cuando sus problemas y la solución que a ellos ofrezca concuerden 
plenamente» (Zea, 1947). El existencialismo mexicano no fue, ni por su contenido ni por sus pretensiones, un trasunto del existencialismo francés.

Los hiperiones tenían una concepción propia de la filosofía: ésta debía ser auténtica, es decir, sensible a sus circunstancias; debía ser una filosofía histórica, «mundana», pragmática, moralizante y salvadora o salvífica; y debía incluir, entre sus estrategias y métodos, la búsqueda electiva de afinidades y la reapropiación creativa de discursos teóricos foráneos. Esta concepción de la filosofía precedió a sus lecturas de Sartre y de Merleau-Ponty. No es en estos pensadores franceses donde debemos rastrear su origen, sino en un artículo de juventud de Zea: $E l$ sentido de responsabilidad de la filosofía actual (1940). «En el parto del existencialismo en México -escribió Francisco Larroyo-, los fórceps que extrajeron la criatura ya preformada fueron la propia literatura existencialista y las enseñanzas en nuestra patria de los españoles "transterrados"» $(1951 ; 206)$.

\section{Tierra Nueva}

En 1940, tres jóvenes estudiantes de José Gaos tuvieron la idea de fundar una revista. Gracias al enérgico espaldarazo de Alfonso Reyes y de Mario de la Cueva (Secretario de la Universidad), este proyecto vio la luz bajo el nombre, optimista y promisorio, de Tierra Nueva (1940-1942). A los fundadores de la revista (Jorge 
González Durán, José Luis Martínez y Alí Chumacero) les había llamado la atención

un joven algo sombrío pero capaz de una concentración y una disciplina sin par, Leopoldo Zea. Aprobamos la elección, nos hicimos amigos del incipiente filósofo que soñaba hasta hacía poco con ser poeta y a quien esperaban tantos triunfos intelectuales, y Leopoldo Zea fue desde entonces el filósofo del grupo y quien luego atrajo a la revista a otros jóvenes pensadores: Manuel Cabrera y Juan Manuel Terán (Martínez, 1961; 117-118).

Leopoldo Zea ya era por entonces una especie de revelación. Un año atrás, en 1939, el doctor Gaos había quedado gratamente sorprendido por los trabajos de este joven lánguido y ojeroso. Zea apenas tenía tiempo para dormir. Alternaba su trabajo en Telégrafos de México con la Universidad, donde cursaba no una sino dos carreras: Derecho y Filosofía. Gaos intervino para que la Casa de España le concediese una beca (la primera que se le otorgaba a nadie). «¿Necesitaré añadir que Zea - se preguntaba Gaos - ha probado superabundantemente con los hechos que merecía todo cuanto Casa de España y Facultad hicieron por él?» (1958; 81).

La timidez de Zea, que tanto intrigaba a sus compañeros de seminario, apenas se percibe en su texto «El sentido de responsabilidad en la filosofía actual», aparecido en el tercer número de Tierra Nueva. La voz que allí se deja escuchar es una voz de indignación y 
urgencia, una voz arrojada, valiente, que señala sin titubeos y sin margen de confusión el rumbo que debe seguir el pensamiento mexicano para no ceder a la tentación del individualismo (cuya consecuencia última sería la erradicación del Estado, o sea, la anarquía) y la tentación de la dictadura (cuya condición de posibilidad es el hombre-masa, o sea, el individuo que decide no empuñar su libertad, decide no decidir, como el «Uno se» heideggeriano).

Zea, en estas pocas páginas, esboza un nuevo programa filosófico que bien podemos llamar «existencialista». Estamos ante el surgimiento del existencialismo mexicano, ya anunciado por Antonio Caso y por Samuel Ramos y por otros tantos intelectuales, pero llevado ahora a su postulación más programática y coherente.

\section{El sentido de responsabilidad en la filosofía actual}

Para Zea, la filosofía no es un ideal utópico ni una abstracción metafísica descarnada y sin ninguna incidencia en la realidad. La filosofía es algo con lo que el individuo se tropieza en el mundo. Así como los peatones tropiezan con una roca en la calle, así cada generación de hombres encuentra en su camino una serie de problemas, aporías o dificultades que le impiden el paso o, mejor dicho, que le impiden vivir, que se oponen a su vida. Y dentro de cada una de estas generaciones, es posible hallar puntos de vista 
diversos. Cada quien, de acuerdo con su personalidad y su posición en el mundo, cree saber la manera de solventar el obstáculo. Ocurre con frecuencia que lo que la generación pasada consideró una solución, represente un problema para la generación actual. No existen fórmulas mágicas y universalmente válidas en la filosofía. Cada generación se enfrenta al reto de buscar y encontrar la mejor solución a sus preocupaciones. Que una solución (una cierta armazón teórica y una cierta praxis) haya funcionado en el pasado, no garantiza que funcione en la actualidad; se corre incluso el riesgo de una disociación entre soluciones y problemas: «en vez que las soluciones concuerden con su circunstancia, se quiere que ésta concuerde con las soluciones» (Zea, 1940; 137). Pensemos en el «bovarismo nacional» de Antonio Caso: este desfase y esta sensación de asfixia que se producen cuando el bovarismo no se pone al servicio de la vida, es decir, cuando el «yo ficticio» se robustece y termina por desligarse del «yo propio» (Caso, 1922; 75-82). O pensemos en el sentimiento de inferioridad de Samuel Ramos, fruto de un desfase patológico entre el modo de ser y el modo de concebirse, hasta el punto de que la representación imaginaria encubre y distorsiona la realidad (Ramos, 1932; 8-11).

La filosofía que bosqueja Zea es una filosofía circunstancial e histórica. Los problemas filosóficos podrán ser personales o colectivos, pero no eternos, más que de nombre. Los problemas cambian al mismo ritmo y en el mismo sentido que la vida; están anclados en sus circunstancias históricas, lo cual no significa que 
cada generación se halle sola y como una especie de Adán en la búsqueda de soluciones adecuadas; cuenta por suerte con la herencia y el sustento histórico. El filósofo, miembro de una generación, a la vez que un individuo con personalidad única, ha de buscar en la historia circunstancias parecidas, paralelismos y simpatías; ha de estudiar de qué manera otras generaciones enfrentaron problemas similares a los actuales, pero no con la intención de importar estas viejas soluciones y estos viejos instrumentos, al menos no con la intención de importarlos incólumes, sin transformarlos ni adaptarlos a los nuevos requerimientos.

La filosofía implica a fortiori estudio de la historia (de la filosofía). Zea no concebía una filosofía que se planteara a sí misma desde cero. El pasado emerge a la vista del filósofo como experiencia pasada. Filosofar es un acto de expoliación en el buen sentido: un acto de recuperación que conlleva innovación, reapropiación, expresión personal y originalísima. El pasado no es no debe ser - para el filósofo, para este nuevo filósofo mexicano, un peso muerto que le quite la libertad. Uno, para de veras ser responsable y libre, para plantarle la cara a sus circunstancias, no puede recoger patrones de vida ya hechos, tiene que proponer y crear los suyos. «La filosofía actual es la del hombre que se enfrenta a su amenazante circunstancia; la del hombre que trata de salvar su libertad, su individualidad» (Zea, 1940; 139).

Esta expresión, «salvar la libertad», equivale en el discurso de Zea a un atreverse a vivir, a actuar, a hacer 
algo con las cosas, no dejarlas como están ni abandonarnos a nosotros mismos a una penosa quietud:

Las preguntas que anteriormente se hacía el hombre sobre lo bueno, lo santo, lo justo, etc., no eran en el fondo sino preguntas sobre lo que había de hacer, sobre cómo había de vivir. Vivir es eso, el tener que actuar, el tener que hacer algo con las cosas, con el mundo, con la circunstancia (Zea, 1940; 139).

La filosofía, en su fondo, siempre ha sido pragmática, ya que, aunque no se lo admita a sí misma, siempre ha andado en busca de orientaciones para el actuar en el mundo: su conclusión última no es un bello silogismo, sino un principio de acción. (Dicho sea de paso, este pragmatismo, este propósito de generar y guiar prácticas concretas, estaba muy en consonancia con las filosofías de Caso y Ramos).

La de Zea es, por consiguiente, una filosofía mundana, es decir, una filosofía del quehacer humano en el mundo, una filosofía sobre el hacer mundo.

El hombre no quiere ser algo hecho, sino algo que él mismo se haga. El hombre no acepta al mundo como es, sino que lo quiere hacer, se trata de un desmundanizar al mundo, a lo cual éste se resiste. Se entabla una lucha entre el hombre y el mundo [...]. Pero no por eso el hombre deja de ser mundo, no por eso deja de ser parte del mundo. Este desmundanizarse sigue siendo 
acción sobre el mundo, sigue siendo vida; la inseguridad continúa, el hombre necesita apoyarse sobre algo, y este apoyo solo se lo puede dar el mundo, sigue dependiendo del mundo, sigue corriendo el peligro de ser mundo, de dejar de ser hombre (Zea; 1940; 140).

La libertad - la libertad de actuar y hacer- es entendida aquí como un peligro y como un estar expuesto y sin apoyo. La vida es, de suyo, inseguridad: ésta y no otra es la piedra angular de la nueva filosofía: la piedra con la que ha tropezado la generación de Zea.

La filosofía actual ha caído en la cuenta de que el hombre es inseguridad, de que su vida, de que la posibilidad de vivir está precisamente en la inseguridad. Es la inseguridad la que mueve al hombre a actuar, es decir, a vivir. Si el hombre lograse escapar plenamente al mundo como lo desea para su salvación, entonces dejaría de vivir, perdería su vida; porque en un mundo seguro, en un mundo hecho por el hombre, conforme a sus deseos, la acción no era necesaria, no habría contra qué actuar, y no habiendo acción no habría vida (Zea, 1940; 140).

La filosofía no se plantea entonces como superación de la inseguridad - aquello equivaldría a plantear la superación de la vida en la muerte - ; se trata en todo caso de un enfrentamiento del hombre-filósofo con la realidad en que vive. En este sentido podemos hablar 
de una filosofía realista y sensual, una filosofía que no rehúye la realidad, sino que persigue su contacto:

En este afán de realismo se busca una relación inmediata con la realidad, una relación directa, se la quiere tocar, sentir [...]. El hombre capta la realidad intuitivamente y la razón la aclara, explica. Así, sin otro supuesto que el de la existencia humana, la filosofía examina la realidad, la expone, la describe, sin afirmar ni negar nada sobre ella. Sólo se va diciendo lo que se ve (Zea, 1940; 140).

El filósofo va a los fenómenos, no inventa, no ensaya escapismos utópicos; comprende lo que de hecho ya pre-comprendemos. Es una filosofía existencial porque, como dijimos, toma como punto de partida la inseguridad de la existencia en su libre hacerse. «La vida humana tiene un carácter que le es peculiar, el de no estar hecha sino el de tener que hacerse» (Zea, 1940; 141).

Tener-que-hacer, o sea, el deber de vivir, de transformar el mundo, supone un habérselas con las experiencias de la historia, supone una vigilancia de esos instrumentos de liberación que otros hombres empuñaron, pero supone, además, un habérselas con los bienes culturales, pues el individuo, lo quiera o no, participa ya, desde que nace, de un idioma, unas costumbres y unos códigos de comportamiento de los que no fue artífice. El individuo descubre que su vida, no siendo una vida hecha, sino un llamado a actuar, está sin embargo entreverada con otras vidas, en 
principio ajenas, a través de un legado y de unos bienes culturales (hechos por otros). «Lo que es propio del hombre, lo que forma su individualidad, su propia vida, es la forma como convive, la forma como aprovecha la vida de los demás, la forma como aprovecha las experiencias de la historia»(Zea, 1940; 142). Hacerse cargo de la propia vida es un hacerse cargo de las vidas de los demás. Podemos afirmar ahora que la nueva filosofía mexicana era o debía ser una filosofía de la cultura y una filosofía de la convivencia, en tanto era o debía ser una reflexión sobre la mejor y más provechosa manera de compartir la vida, de hacer vida juntos, acompañados - dejándonos acompañar - de nuestros antepasados afines y de nuestros coetáneos.

Es - debía ser - una filosofía de la salvación, no de salvadores.

La filosofía de nuestros días busca la salvación en un sentido de responsabilidad. Rechaza todo absolutismo del pensamiento [...] porque ve en ellos instrumentos de dominio de determinados sujetos [...]. Aceptar un fin ajeno al hombre, tener un destino predeterminado, un futuro hecho, es anular al hombre como tal. La salvación del hombre está en su individualidad, en lo que le es propio, y al hombre sólo le es propio el hacer su vida (Zea, 1940; 143-144).

De este modo queda aliviada la presunta oposición entre los valores que llamamos personales y los valores sociales: ambos se comunican, se entrelazan. Y por esto mismo, porque estamos ante una filosofía de la vida, 
pero de una vida que es histórica, vida de un individuo y de una generación, es que estamos también ante una filosofía perspectivista en que las construcciones teóricas adolecen de un carácter trascendente o absoluto. «Tales construcciones [metafísicas] dejan de ser absolutas y se convierte en puntos de vista, en visiones que sobre el mundo han tenido determinados sujetos» (Zea, 1940; 144).

El ser hombre o, mejor dicho, el hacerse hombre, es un proceso de naturaleza inconcluso. Si el hombre es ante todo libertad, y la libertad es la acción de hacer mundo, entonces una vida hecha o consumada con arreglo a los deseos del hombre, una humanidad que ha terminado de hacerse - ésta es la aporía de la libertad- ya no es, por definición, ni libre ni responsable. Puestas así las cosas, el ser mexicano o el hacerse mexicano - el dar a luz a este nuevo hombre emanado de la Revolución - es una misión conjunta e inacabable. Nadie nunca se jactará de haber hecho al mexicano, de contar con su definición; nadie, más que el dictador, o su antípoda, el hombre-masa. Únicamente ellos dos podrían asegurar, irresponsablemente, que el mexicano es esto o aquello, determinarlo, fijarlo en una entidad cerrada, ya hecha: sustancializarlo. Este último vocablo no figura en el artículo de Zea, pero de alguna manera se insinúa. Será el primus inter pares de los hiperiones, Emilio Uranga, quien lleve a cabo el análisis fenomenológico de la «sustancia»y el «accidente».

El saldo de todo lo anterior es una filosofía circunstancial, histórica, vital, pragmática, mundana, 
sensual, existencial, perspectivista; filosofía de la salvación, la libertad, la responsabilidad y la convivencia; filosofía de alcance universal o con la capacidad de universalizarse, de proponer - no imponer - soluciones a los hombres contemporáneos del sur o del otro lado del Atlántico. Apta para salir de la reclusión académica y comunicarse con el hombre de a pie.

El filósofo debe de ser una especie de ojos de la sociedad [...]. Debe plantearse los problemas de la sociedad, de su época, de la vida de los que con él conviven y buscarles soluciones para que esos otros las adapten o busquen otras si no son suficientes. Al filósofo corresponde una tarea pedagógica, una tarea de enseñanza [...]. Al filósofo corresponde la tarea de enseñar a vivir, la tarea de enseñar a comportarse ante la realidad (Zea, 1940; 146).

Los más notables filósofos mexicanos entendían la filosofía justo así: como una tarea de enseñanza (Vasconcelos desde la Secretaría de Educación Pública, Antonio Caso desde la tribuna del salón y del periodismo) y como el deber cívico de dictar orientaciones generales de comportamiento (el diván psicoanalítico de Ramos). Da la impresión de que Zea, el superabundante Zea, con su «aire persistente de fatiga, de sueño»(Gaos, 1958; 80), supo recoger y cristalizar en una concepción unitaria de «filosofía» las principales lecciones de sus maestros, los nacionales y los de fuera. Guillermo Hurtado (2019; 9-51) ha logrado 
discernir los ingredientes de esta nueva filosofía mexicana: el circunstancialismo de Ortega y Gasset, el heideggerianismo que perfumaba el ambiente y que perfuma todo el artículo, la noción de «responsabilidad» de Karl Mannheim (el hombre responsable no entrega toda su libertad al líder, pero tampoco enarbola esta libertad para acrecentar su ego y desentenderse de los otros), y, quizá, el concepto de engagement (Landsberg, 1937).

Con la tesis de la inseguridad primordial de la vida, la idea de que la existencia es ante todo un quehacer y con su rechazo a cualquier absolutismo y determinismo, Zea no sólo sentaba las bases, sino que afianzaba la presencia de una nueva corriente de pensamiento que bien podemos llamar existencialismo mexicano. Esta nueva corriente no era, como algunos todavía sospechan o querrían, una sucursal en México del existencialismo francés. Zea no era un seguidor empedernido y precoz de Sartre, cuyo libro más denso, ensalzado a libro de cabecera del existencialismo francés, El ser y la nada, sería publicado en Europa hasta 1943, y cuya recepción en nuestro país, relativamente temprana, en 1947, correría a cargo de Juan David García Bacca (1947; 295-300). Podemos detectar, eso sí, recurriendo al vocabulario del propio Zea, simpatías entre dos generaciones de intelectuales, una mexicana y otra francesa, tocadas ambas por el hálito de la guerra, aunque en niveles e intensidades muy distintas, y lectoras originales ambas de Husserl y Heidegger. 


\section{¿Filosofía mexicana o}

filosofía americana?

Zea caracterizó a la nueva filosofía (mexicana), pero no la bautizó con ningún nombre específico ni la identificó con ningún autor u obra. Zea no parecía sentir especial predilección por términos como «mexicano» o «lo mexicano». Él preferirá hablar en el futuro de una «filosofía americana», extrapolando la circunstancia propia de México (como el sentimiento de inferioridad) al resto del continente. Evidencia de esto fue su artículo «En torno a una filosofía americana», publicado ya no en Tierra Nueva sino en el tercer número de Cuadernos americanos, una revista fundada en 1942 por iniciativa del español Juan Larrea Celayeta y dirigida por Jesús Silva Herzog, con el empuje y la impronta de Alfonso Reyes.

En su artículo, Zea confiere a la nueva filosofía, esta vez «filosofía americana», la proyección universal y el poder de continuidad y de síntesis que Reyes ya había defendido antes, cuando nos describía la «hora de América» como el esfuerzo por merecer, salvaguardar y seguir cosechando los tesoros de la ruinosa civilización occidental.

Esa tarea de tipo universal y no simplemente americano, tendrá que ser el supremo afán de nuestra posible filosofía. Esta nuestra filosofía no debe limitarse a los problemas propiamente americanos, a los de su circunstancia, sino a los 
de esa circunstancia más amplia en la cual también estamos insertos como hombres que somos, llamada Humanidad (Zea, 1942; 78).

Zea se hacía eco de esa hermosa y bien lograda metáfora de Reyes en su «Discurso por Virgilio»: «sin abdicar nuestra dignidad de individuos, todos nos sabemos atados en igual tronco» (Reyes, 1960; 170).

\section{Conclusión}

Zea trabajaba por entonces (1940-43) en su investigación sobre el positivismo mexicano decimonónico, bajo la dirección de Gaos. Su tesis recibiría un aplauso unánime y sonoro. El Universal la proclamaría la mejor tesis del año y su joven e introvertido autor sería elevado a «símbolo de la nueva generación filosófica» (Arai, 1943; 8). Con el apoyo de la Fundación Rockefeller, Zea recorrió las dos Américas. Regresó a México en 1946, a ocupar el lugar del difunto Caso en la cátedra de Filosofía de la Historia. Poco después, en 1947, motivó a sus alumnos a que formaran un grupo de estudio: el Grupo Hiperión. Y en 1948 dio a la imprenta sus Ensayos sobre filosofía en la historia. Se trataba de una compilación de artículos.

Alí Chumacero, su antiguo compañero de seminario, hizo explícita la conexión entre el existencialismo juvenil de Zea, por decir así, y el posterior existencialismo de aliento francés. 
Notamos cómo en estos ensayos, sobre todo el que se titula «El sentido de responsabilidad en la filosofía actual» - publicado inicialmente en Tierra Nueva, 1940 - afloran algunos temas que en estos momentos se han puesto en moda por medio de la filosofía existencial. El «ser para la muerte» de Heidegger y la «libertad en situación» de Jean Paul Sartre son intuidos desde la perspectiva historicista en que desde entonces se situaba Leopoldo Zea. En estos Ensayos encontramos sin dilación prefiguradas las tesis que actualmente discute y estudia, con cotidiano ahínco, nuestro joven filósofo, de manera que su desviación hacia el existencialismo, en cuya cátedra se halla Sartre, no resulta de ninguna manera la resultante de una curiosidad filosófica, sino el descubrimiento del implícito compromiso contraído con la filosofía (Chumacero, 1948).

Debemos a Leopoldo Zea la convicción seminal del existencialismo mexicano, a saber, la convicción de que la filosofía no es un quehacer abstracto y desligado de la vida cotidiana, sino un quehacer circunstancial, mundano, pragmático, responsable y auténtico. A esta lista se añadirán otros adjetivos, ya de influencia sartreana: filosofía comprometida y en situación.

A finales de los cuarenta, los artículos de juventud de Leopoldo Zea eran más vigentes que nunca. La guerra había terminado, pero no la atmósfera de inseguridad e incertidumbre. Se hizo más evidente que 
nunca la necesidad de una filosofía nacional que fuese, al mismo tiempo, filosofía universal y para todos. La propia UNESCO urgía a los filósofos de todas las latitudes a que se reunieran y crearan cuanto antes esta nueva filosofía. Zea y los hiperiones tenían en mente aquello que Vasconcelos solía decir: si a un europeo pongamos, a un alemán - se le pregunta quiénes son los hombres más importantes, responderá, con total seguridad, Kant, Goethe, Hegel. En cambio, si se le pregunta a un latinoamericano, éste no dudará en responder que Platón, Sócrates, Descartes, Kant, Goethe, Hegel, Lincoln, además de los suyos (Hidalgo, Bello, Sierra). Los latinoamericanos tenían motivos para sentirse doblemente orgullos: no tenían problemas en asimilar y en vivenciar como propias las conquistas de la Humanidad. De aquí que Zea se haya dedicado en este período (1947-50) a elaborar su vieja tesis de una filosofía americana y universal:

El universalismo, del que tanto ha presumido Europa, se encuentra más eficazmente expresado en la mentalidad americana. Si se agudiza más se llega a la conclusión de que lo que la inteligencia europea ha preconizado como universalismo no es otra cosa que una justificación de su ignorancia o de su incapacidad para entender otras culturas; en cuanto que no hace otra cosa que medir a éstas con los moldes de lo que les propio, a decir, dentro de ciertos límites, rechazando todo lo que no cabe dentro de estos moldes... Vamos a llamar imperialismo a ese afán por medir la obra 
realizada por otros pueblos con determinados moldes hechos... Los términos han sido invertidos: lo universal no es ya imposición de una parte e imitación de la otra: lo universal es ahora recibo, y aportación: recibir y dar... Este Continente, consciente de sus capacidades y responsabilidad, abandona tutelas, lo cual no significa, como temen algunos, negar o renegar de lo recibido, sino simplemente capacidad para dar (Zea, 1947).

El existencialismo mexicano se convirtió, para Zea, en una filosofía latinoamericana. Para los hiperiones, en una «filosofía de lo mexicano». Ambas compartían una vocación universal, pero de una universalidad compleja, más parecida a la comprensión y a la compenetración que a la imposición autoritaria.

\section{Bibliografía}

Arai, A. T. (1943). Leopoldo Zea, de la nueva generación filosófica. Letras de México (7), 8.

Caso, A. (1922). El bovarismo nacional. En Discursos a la nación mexicana. México: Porrúa.

Chumacero, A. (1948). Acerca de un filósofo mexicano. El Nacional (6).

Gaos, J. (1958). Confesiones profesionales. México: Fondo de Cultura Económica.

García Bacca, J. D. (1947). L'Etre et le Néant (J.P. Sartre). Filosofía y letras (26), 295-300. 
Hurtado, G. (2019). Introducción: las mocedades de Leopoldo Zea, en Zea, L. Escritos de Juventud, 1933-1942. México: Universidad Nacional Autónoma de México, 9-51.

Larroyo, F. (1951). El existencialismo, sus fuentes y direcciones. México: Stylo.

Martínez, J. L. (1961). El trato con escritores. México: Institudo Nacional de Bellas Artes.

Ramos, S. (1932). Psicoanálisis del mexicano. Examen (1), 8-11.

Reyes, A. (1960). Discurso por Virgilio. Obras completas XI. México: Fondo de Cultura Económica.

Zea, L. (1940). El sentido de responsabilidad en la filosofía actual. Tierra Nueva (3), 136-146.

Zea, L. (1942). En torno a una filosofía americana. Cuadernos Americanos (3), 63-78.

Zea, L. (1947a). México y su independencia cultural. El Nacional (3).

Zea, L. (1947b). La filosofía en México. Alfonso Reyes y la inteligencia americana. Revista Mexicana de Cultura (16), 5. 